\title{
Retinal Ganglion Cell Complex Changes after Intravitreal Bevacizumab for Diabetic Macular Edema
}

\author{
Muhammad Shaheer, Arooj Amjad and Zubair Saleem
}

\begin{abstract}
Objective: To measure the changes in ganglion cell complex as measured on optical coherence tomography (OCT) after intravitreal injection of bevacizumab (Avastin).

Study Design: Quasi-experimental study.

Place and Duration of Study: Department of Ophthalmology, Lahore General Hospital, Lahore, from March 2017 to April 2018.

Methodology: Patients presenting to the Eye OPD were assessed for diabetic macula edema requiring intravitreal injection of anti-VEGF. Patients having any coexisting ocular pathology hindering the OCT measurement, i.e. corneal opacity, vitreous hemorrhage, retinal detachment or having macular edema secondary to other cases were excluded. Retinal ganglion cell complex thickness and signal strength was measured in superior, inferior, supero-nasal, superotemporal, infero-nasal and infero-temporal quadrants on OCT. Pre-injection, visual acuity was measured, OCT performed and the findings were recorded on a designed proforma. Post-injection, the patients were called for follow-up after one month at which time same measurements were evaluated. All the injections were administered by a single surgeon.

Results: The thickness of ganglion cell complex increased significantly $(p<0.001)$ one month after Intravitreal injection of bevacizumab.

Conclusion: Intravitreal administration of bevacizumab in diabetic macular edema affects the measurement of retinal ganglion cell complex thickness on OCT.
\end{abstract}

Key Words: Bevacizumab, Ganglion cell complex, OCT, Diabetic macular edema.

\section{INTRODUCTION}

Diabetic retinopathy is one of the commonest microvascular complications of diabetes mellitus. ${ }^{1}$ Diabetic retinopathy may progress to a permanent visual loss with suboptional glycemic control. Of all the reasons of visual deterioration of loss due to diabetic retinopathy, diabetic macular edema is the most prevalent one.2 diabetic macular edema may affect the eye during any stage of diabetic retinopathy, and if not treated promptly, it may lead to permanent visual loss. ${ }^{3}$ Diabetic macular edema is affected by many systemic factors such as glycemic control, dyslipidemia, 4 hypertension and pregnancy. 5 With time, intravitreal administration of drugs has become a popular mode of treatment for various disorders involving the retina and vitreous, i.e. diabetic retinopathy, central retinal vein occlusion, 6 viral infections of posterior segment and most importantly endophthalmitis. ${ }^{7}$ The advantage of intravitreal administration of drug is a speedy achievement of minimum inhibitory concentration at the desired site and less systemic absorption.

Department of Ophthalmology, Lahore General Hospital /

Postgraduate Medical Institute, Lahore, Pakistan

Correspondence: Dr. Muhammad Shaheer, Department of

Ophthalmology, Lahore General Hospital / Postgraduate

Medical Institute, Lahore, Pakistan

E-mail: mshaheer212@gmail.com

Received: August 07, 2018; Accepted: November 17, 2018
Bevacizumab is a monoclonal antibody which, when injected into the vitreous cavity, decreases the retinal vessel's permeability and also accelerates the absorption of fluid already present in the retinal layers. ${ }^{8}$ Bevacizumab is the most commonly used anti-vascular endothelial growth factor inhibitor owing to its easy availability and lower price as compared to other commercially anti-vascular endothelial growth factor preparations. The duration of action of bevacizumab is around four weeks after which time it can be repeated if indicated. 9

Ganglion cell complex comprises of two vital layers of retina, i.e. ganglion cell layer and inner plexiform layer. The structure and thickness of these two vital layers is important because they are prone to damage by raised intraocular pressure causing glaucoma. 10 Untill now, a lot of research has been done of various ocular disorders and interventions on the anatomy of ganglion cell complex, but very less is known about the effect of intravitreal injections on the anatomy of this complex. ${ }^{11}$ Optical coherence tomography (OCT) is a modern noninvasive mode of getting the three dimensional microresolution images of all layers of retina. ${ }^{12}$ It enables the ultra structural imaging of all layers and helps in the study of any changes in the retinal layers secondary to any ocular or systemic factor. ${ }^{13}$

The objective of this study was to measure the changes in retinal ganglion cell complex after intravitreal injection of bevacizumab in patients with diabetic macular edema. 


\section{METHODOLOGY}

Ethical approval of this quasi-experimental study was obtained from "Ethical Review Committee" of Lahore General Hospital, Lahore which was conducted from March 2017 to April 2018. Patients presenting to the Eye OPD, Lahore General Hospital were assessed. Patients (n-64) diagnosed on slit lamp examination (macular thickening and exudates) with diabetic macular edema and confirmed and quantified by OCT were selected by non-probability consecutive sampling and were included in the study (Figure 1).

Patients having any coexisting ocular pathology hindering the OCT measurement, i.e. corneal opacity, vitreous hemorrhage, or retinal detachment were excluded. Retinal ganglion cell complex thickness was measured by OCT (Zeiss Cirrus HD OCT 5000/500) in six quadrants, i.e. superior, inferior, supero-nasal, supero-temporal, infero-nasal, and infero-temporal using the macular cube protocol.

Besides, signal strength on OCT was also documented. Pre-injection, visual acuity was measured, OCT performed, and findings were recorded on a pre-designed proforma.
After aseptic measures, opsite was applied on the eye to be injected. An area was identified $4 \mathrm{~mm}$ from the supero-temporal limbus after instilling proparacaine $\mathrm{HCL}$ anesthetic eye drops. Intravitreal bevacizumab injection was injected from that point into the vitreous cavity. The injected site was kept pressed with a cotton pledget to avoid any oozing of the agent out of the vitreous cavity.

Tobramycin antibiotic drops were instilled and eye pad was applied. Patients were then advised tobramycin antibiotic eye drops four times daily for one week. The patients were called for follow-up after one month; at which time, visual acuity was again measured and OCT performed and findings recorded in the proforma. Intravitreal Injection was repeated, if indicated, and patients were again called for one month follow-up for the treatment review. All the procedures were performed by single surgeon.

Data analysis was carried on SPSS version 22 for Windows. Quantitative variables were presented as their mean and standard deviation values. However, the qualitative variables were presented as frequencies and percentages. Paired samples t-test was applied to determine the difference between the ganglion cell

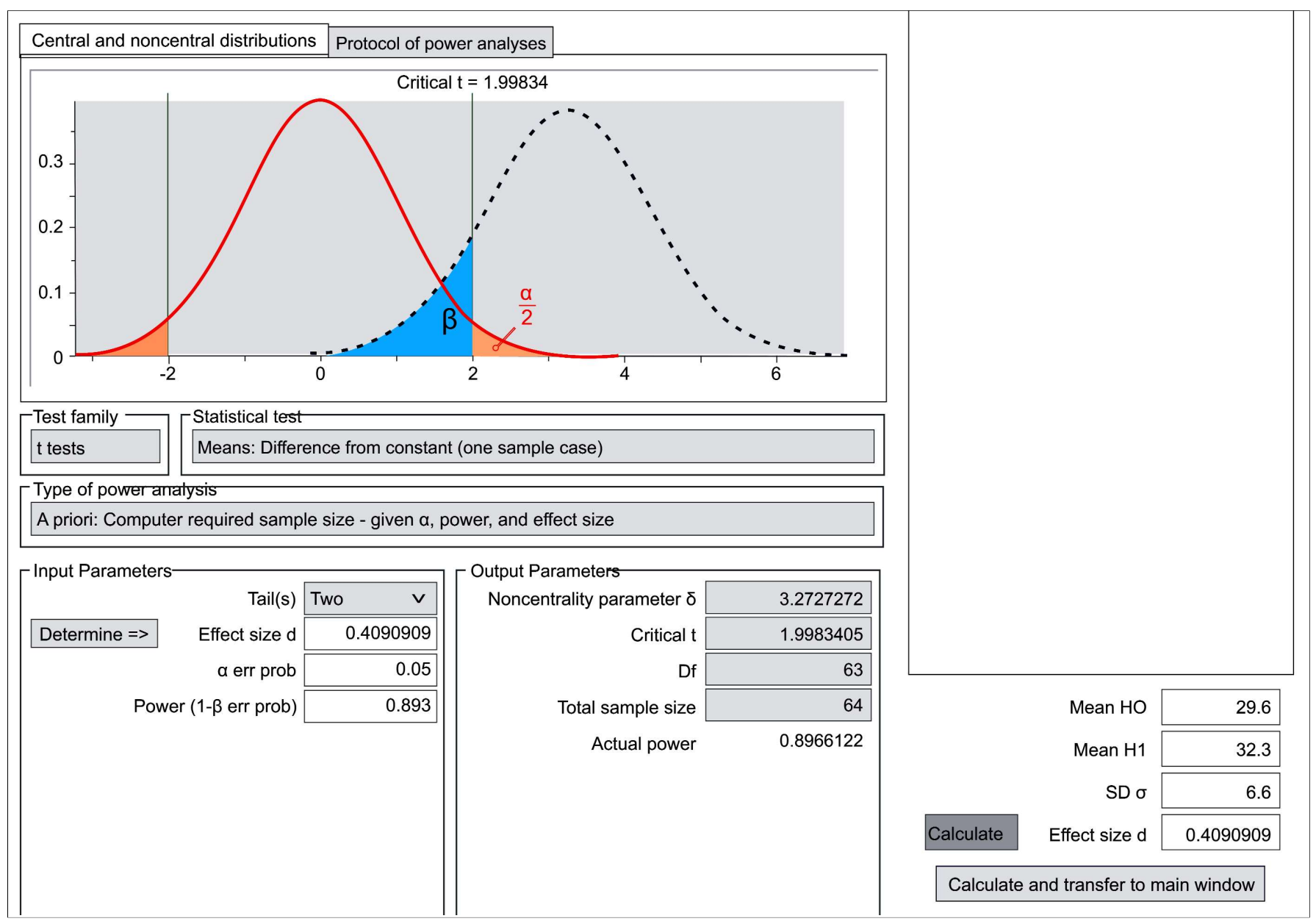

Figure 1: Sample size study (study GCC after avastin) 
complex thickness of pre-surgery and one month postsurgery. P-value $\leq 0.05$ was considered statistically significant.

\section{RESULTS}

The mean age of patients was $60.20 \pm 5.25$ years. Of the 64 patients, $36(56.3 \%)$ were male and $28(43.8 \%)$ were female patients. Injection was given in the left eye of 29 $(45.3 \%)$ patients and in right eye of $35(54.7 \%)$ patients. Pre-injection visual acuity was 6/36 in 15 (23.4\%) patients, $6 / 60$ in $40(62.5 \%)$ patients, hand movement at one foot in $4(6.3 \%)$ patients, and counting fingers at one foot in $5(7.8 \%)$ patients. Post-injection visual acuity was $6 / 36$ in $18(28.1 \%)$ and $6 / 60$ in $46(71.9 \%)$ patients.

The pre-injection mean geographical ganglion cell complex thickness was $81.86 \pm 2.99 \mu \mathrm{m}$, and 80.44 $\pm 3.03 \mu \mathrm{m}$ one month after injection.

The changes in ganglion cell complex thickness and signal strength were statistically significant before and after the procedure (Table I).

Table I: Ganglion cell complex thickness changes after intravitreal avastin.

\begin{tabular}{l|c|c|c}
\hline Parameter & Pre-injection & $\begin{array}{c}\text { One month } \\
\text { post-injection }\end{array}$ & p-value \\
\hline Total & $81.86 \pm 2.99$ & $80.44 \pm 3.03$ & $<0.001$ \\
Superior & $81.56 \pm 2.97$ & $80.38 \pm 3.11$ & 0.034 \\
Inferior & $81.50 \pm 2.96$ & $79.91 \pm 2.70$ & 0.002 \\
Infero-nasal & $80.97 \pm 3.04$ & $79.94 \pm 3.03$ & 0.051 \\
Supero-nasal & $81.70 \pm 3.13$ & $80.50 \pm 3.26$ & 0.024 \\
Supero-temporal & $81.48 \pm 3.05$ & $80.13 \pm 3.17$ & $<0.001$ \\
Infero-temporal & $82.47 \pm 3.27$ & $81.27 \pm 3.33$ & 0.041 \\
Signal strength & $8.30 \pm 0.68$ & $8.56 \pm 0.50$ & 0.002 \\
\hline
\end{tabular}

Continuous variables were presented as Mean \pm Standard Deviation.

Paired sample T-test was applied. P-value $\leq 0.05$ was considered as significant.

Ganglion Cell Thickness was measured in microns.

\section{DISCUSSION}

The authors described the changes in retinal ganglion cell complex changes after injection of intravitreal Bevacizumab for the treatment of diabetic macular edema. It showed a decrease in retinal ganglion cell complex one month after treatment. The thickness was decreased in all the quadrants measured as well as globally. The change in thickness after intravitreal Bevacizumab were statistically significant. None of the patients were diagnosed with glaucoma during the study period.

Bonin et al. studied the ganglion cell complex thickness changes after resolution of macular edema after treatment. 14 In their study, average ganglion cell complex thickness was reduced in eyes treated for diabetic macular edema as compared to the eyes which had no diabetic macular edema. The study also showed a correlation between visual acuity and the thickness of ganglion cell complex thickness in eyes with diabetic macular edema. They concluded that despite a great anatomic response to treatment, the ganglion cell complex thickness decreased in patients of diabetic macular edema which correlated with visual acuity.

Keampf et al. studied the effects of bevacizumab on retinal cells in organotypic culture. 15 Their study showed no toxic effects on ganglion cell or photoreceptors at any concentration of bevacizumab. An increased smooth muscle antibody was noted in retinal blood vessels which was due to loss of vascular endothelial growth factor modulating smooth muscle cells. The study concluded that bevacizumab is not toxic to the retinal ganglion cells at concentrations five times greater than used routinely.

Schraermeyer et al. studied the role of bevacizumab on retina and choroid after intravitreal injection into monkey eyes. ${ }^{16}$ The study showed that bevacizumab accumulated in the retinal blood vessels as deposits and could lead to interrupted blood flow. Thus these deposits may be the mechanical evidence for the blood flow alterations observed in patients treated with bevacizumab.

Perdicchi et al. studied changes in ganglion cell complex changes after treatment of age related macular degeneration with intravitreal ranibizumab. ${ }^{17}$ Their study showed an average of $8.1 \pm 20.2 \mu \mathrm{m}$ after a single injection of intravitreal ranibizumab. This decrease in retinal ganglion cell complex thickness was statistically significant, although the visual acuity and central macular thickness were reduced. But they were not sure if repeated intravitreal injections of anti-VEGF progressively decreased the ganglion cell complex thickness.

Beck et al. studied retinal ganglion cell complex changes after treatment of neovascular age related macular degeneration with intravitreal anti-VEGF agents. ${ }^{18}$ They studied both the retinal ganglion cell and retinal nerve fiber layer changes after anti-VEGF intravitreal injection. The study found statistically significant decrease in the retinal ganglion cell thickness, but the retinal nerve fiber layer thickness changes were not significantly affected.

Rimayanti et al. studied ganglion cell complex and retinal nerve fiber layer changes in patients with neovascular age related macular degeneration as compared to patients with dry age related macular degeneration and glaucoma. ${ }^{19}$ They found different ganglion cell complex values in normal subjects and those with both dry and wet age related macular degeneration with glaucoma and correlated with disease severity.

Lee et al. studied the changes in retinal ganglion cell complex thickness after treatment of central retinal vein occlusion with intravitreal anti-VEGF agents. 20 They have found a significant decrease in retinal ganglion cell complex thickness after multiple injections of intravitreal anti-VEGF. This change in thickness correlated with central macular thickness and number of injections.

Michalewski et al. studied the morphological changes on OCT after bevacizumab injections for the treatment of wet age related macular degeneration. ${ }^{21}$ They have 
found in their study that long term therapy with antiVEGF agents leads to the formation of defects in the junction of inner and outer segments of photoreceptors.

Chhablani et al. studied the changes in retinal ganglion cell complex in patients of idiopathic macular telangiectasia type 2A.22 Their study showed a significant and consistent retinal ganglion cell complex degeneration leading to a diffuse thinning.

Presence of varying results in international literature and absence of local literature on this subject was the rationale to conduct this study. Still this study was limited as the effects were observed after a single intravitreal injection. So the authors suggest a randomised controlled trial to see if the effects of bevacizumab leads to a progressive decrease in ganglion cell complex thickness after multiple intravitreal injections.

\section{CONCLUSION}

Intravitreal injection of bevacizumab does affect the thickness of retinal ganglion cell complex.

\section{REFERENCES}

1. Nentwich MM, Ulbig MW. Diabetic retinopathy-ocular complications of diabetes mellitus. World J Diabetes 2015; 6: 489-99.

2. Varma R, Bressler NM, Doan QV, Gleeson M, Danese M, Bower JK, et al. Prevalence and risk factors of diabetic macular edema in the United States. JAMA Ophthalmol 2013; 132:1334-40.

3. Mitchel P, Wong TY. Management paradigms for diabetic macular edema. Am J Ophthalmol 2014; 157:505-13.e1-8.

4. Das R, Kerr R, Chakravarthy U, Hogg RE. Dyslipidemia and diabetic macular edema: A systematic review and metaanalysis. Ophthalmology 2015; 122:1820-7.

5. Concillado $M$, Andersen HL, Mathiesen ER, Larsen M. Dexamethasone intravitreal implant for diabetic macular edema during pregnancy. Am J Ophthalmol 2016; 165:7-15

6. Campochiaro PA, Sophie R, Pearlman J, Brown DM, Boyer DS, Heier JS, et al. Long-term outcomes in patients with retinal vein occlusion treated with ranibizumab: The RETAIN study. Ophthalmology 2014; 121:209-19.

7. Storey P, Dollin M, Pitcher J, Reddy S, Vojtko J, Vander J, et al. The role of topical antibiotic prophylaxis to prevent endophthalmitis after intravitreal injection. Ophthalmology 2014; 121:283-9.

8. Wells JA, Glassman AR, Ayala AR, Jampol LM, Aiello LP, Antoszyk AN, et al. Aflibercept, bevacizumab or ranibizumab for diabetic macular edema. N Eng J Med 2015; 371:1193-1203.

9. Krohne TU, Muether PS, Stratmann NK, Holz FG, Kirchhof B, Meyer $\mathrm{CH}$, et al. Influence of ocular volume and lens status on pharmacokinetics and duration of action of intravitreal vascular endothelial growth factor inhibitors. Retina 2015; 35:69-74.
10. Kim HJ, Lee SY, Park KH, Kim DM, Jeoung JW. Glaucoma diagnostic ability of layer-by-layer segmented ganglion cell complex by spectral-domain optical coherence tomography. Invest Ophthalmol Vis Sci 2016; 57:4799-4805.

11. Demirel S, Batioglu F, Ozmert E, Erenler F. The effect of multiple injections of ranibizumab on retinal nerve fiber layer thickness in patients with age related macular degeneration. Curr Eye Res 2015; 40:87-92.

12. Kuehlewein L, Sadda SR, Sarraf D. OCT angiography and sequential quantitative analysis of type 2 neovascularization after ranibizumab therapy. Eye (Lond) 2015; 29:932-5.

13. de Carlo TE, Chin AT, Bonini Filho MA, Adhi M, Branchini L, Salz DA, et al. Detection of microvascular changes in eyes of patients with diabetes but not clinical diabetic retinopathy using optical coherence tomography angiography. Retina 2015; 35 : 2364-70.

14. Bonin S, Tadayoni R, Erginay A, Massin P, Dupas B. Correlation between ganglion cell thinning and poor visual function after resolution of diabetic macular edema. Invest Ophthalmol Vis Sci 2015; 56:978-82.

15. Kaempf S, Johnen S, Salz AK, Weinberger A, Walter $P$, Thumann G. Effects of bevacizumab (Avastin) on retinal cells in organotypic culture. Invest Ophthalmol Vis Sci 2008; 49: 3164-71.

16. Schraermeyer $U$, Julien $S$. Effects of bevacizumab in retina and choroid after intravitreal injection in monkey eyes. Expert Opin Biol Ther 2013; 13:157-67.

17. Perdicchi A, Peluso G, lacovello D, Balestrieri M, Fave MD, Abdolrahimzadeh S, et al. Ganglion cell complex evaluation in exudative age related macular degeneration after repeated intravitreal injections of ranibizumab. Biomed Res Int 2015; 2015:268796.

18. Beck M, Munk MR, Ebneter A, Wolf S, Zinkernagel MS. Retinal ganglion cell change in patients treated with anti-vascular endothelial growth factor for neovascular age related macular degeneration. Am J Ophthalmol 2016; 167:10-7.

19. Rimayanti U, Kiuchi $Y$, Yamane K, Latief MA, Mochizuki H, Hirata $J$, et al. Inner retinal layer comparisons of eyes with exudative age related macular degeneration and eyes with age related macular degeneration and glaucoma. Graefes Arch Clin Exp Ophthalmol 2014; 252:563-70.

20. Lee JY, Kim HC. Ganglion cell layer thickness after antivascular endothelial growth factor treatment in retinal vein occlusion. J Korean Ophthalmol Soc 2016; 57:63-70.

21. Michalewski J, Nawrocki J, Idzebski B, Michalewska Z. Morphological changes in spectral domain optical coherence tomography guided bevacizumab injections in wet age related macular degeneration, 12 months results. Indian J Ophthalmol 2014; 62:554-60.

22. Chhablani J, Rao HB, Begum VU, Jonnadulla GB, Gaud A, Barteselli G. Retinal ganglion cell thinning in eyes with nonproliferative idiopathic macular talengactesia type 2A. Invest Ophthalmol Vis Sci 2015; 56:1416-22. 